\title{
ASOCIAL DISPLAY OF CHILDREN'S AND YOUTH'S BEHAVIOUR (A PROBLEM OF THE PRESENT-DAY ELEMENTARY AND SECONDARY SCHOOLS)
}

\begin{abstract}
Alena Valisova
doi: 10.18355/PG.2022.11.1.7

Abstract

Professionals, together with the public, pay attention to the growing negative display of the children's and youth's behavior that can be nowadays encountered at the elementary and secondary schools. The character of undesirable behavior display ranges from difficulties manageable by standard pedagogical measures up to such behavioral disturbances which, due to its dangerousness for the disturbance bearer and his surroundings as well, eliminate the individual from the normal social relations. In the following text, attention is paid to the behavioral problems at schools nowadays that are not a phenomenon only in the Czech school system but also in the international context.
\end{abstract}

\section{Key words}

Asocial behavior, behavioral disturbances, addictions, the criminality of youth, pedagogical intervention, preventive and social rehabilitation care, diagnostic activity, consultancy services, the role of the family, pedagogical and psychological counseling, children's psychiatry

\section{Main reasons of social - pathological phenomena and conceptual labyrinth}

Categorization of the socially undesirable display of children's and youth's behavior and its definition in the professional literature is ambiguous. Its content definition depends on the conception of the legal conscience, on the extent of the social seriousness of such behavior, and on the criminal liability for the committed actions.

Quite frequently, we are encountered by the following terms:

- $\quad$ socially - pathological phenomena (summarizing the concept for undesirable, abnormal behavior that with its negative consequences endangers both its bearer and the whole society);

- asocial behavior (inconsiderate behavior that does not correspond to the moral standards of the given society);

- antisocial behavior (it is characterized by a high degree of social dangerousness, the realization of the criminal activity, it is usually connected with intentional verbal and physical aggression);

- delinquent behavior (socially undesirable up to deliberate antisocial behavior in a broader sense than criminality, a term denoting 
commitment of criminal offenses and also misdemeanors or other wrongs);

- $\quad$ syndrome of risky behavior in adolescence - SRCH-D (a complex of negative effects in adolescence that are detrimental to the development of the adolescent, his life, health, and integration into the society).

Attempts to explain the socially-pathological phenomena were aimed at searching for reasons in the following factors:

biological, in the hereditary or innate load (criminal anthropology), the influence of the race (genealogical studies, theory of the racial inequality), in psychological factors represented by disturbances of the personality structure, extreme psychical loads, the discrepancy between human spontaneity and cultural needs (id, ego, and superego - psychoanalytical school), in acquired social behavior (theory of learning, theory of imitation) and in the social factors, particularly in the pathological structure of the family and other primary social groups, in the creation of the specific subcultures and contracultures, the influence of the mass media, in the establishment of the welfare and consumer society, in the concentration of inhabitants in the big cities (theory of differential association, theory of pressure, theory of inhibitions and other things).

\section{Classification of the socially-pathological phenomena and its characteristics}

In view of the fact that nowadays does not exist a definitely accepted and used classification of the socially pathological phenomena, the following characteristics are particularly focused on psychological and social aspects of the undesirable display of children's and youth's behavior in the context of the pedagogical practice (Jedlička and the team of authors, 2015, p.350-365). In the course of prevention, diagnostics, re-education, and pedagogicalpsychological support of children and adolescents in difficult life situations, it is necessary to keep in mind that the display of their behavior, the way of their thinking, and specifics of their experience are always complicatedly conditioned by many mutually emphasized or on the contrary, neutralized circumstances (the text is particularly based on the publication Jedlička in Vališová, Kasíková and the team of authors, 2011, p. 363-422; Průcha and the team of authors, 2009, p. 217-233; Vališová, Kovaříková, 2021, p. 271291).

\subsection{Behavioural problems and behavior disturbances}

To these problems belong behavioral disturbances that used to be a sideeffect or result of the disrupted pedagogical process or broader social relations. The problems differ in the intensity of its display and the possibility of its elimination, it can have an interim character, and it can be emendable by a suitable activity. In case the problems stay unrecognized or overlooked, 
it can then expand to more serious socialization problems in adolescence or adult age.

\section{a) Defiance}

It is a gesture of defiance towards the limiting pedagogical measures (around the age of three years -1. period of defiance, in the adolescence -2 . period of defiance). Defiance can either have a passive form - flight into isolation, negativism, or an active form - aggressiveness up to destructiveness. Excessive bans and orders, perfectionist or authoritarian upbringing, cause a reactive behavior that results in defiance, disobedience, and destruction. It is always necessary to trace down the reason and search for the causes why, against whom, or in which situations such behavior occurs.

\section{b) Lying and deceptions}

A lie can be approached as a knowingly or deliberately manifested untruth. The person, by speaking untruth, pursues with such action basically a certain target. To the true lies cannot be counted entirely groundless lying, fable lying, nor various assertions of persons with low intellect and some mentally ill persons.

Lie in the younger school-age can be a gesture of uncontrolled imagination. For children and adolescents, it can be an attempt to protect oneself, an effort

110 to avoid troubles, or a desire to attract attention. The lie cannot be underestimated. It can be a significant display of mental disease (for example, fallacies at mental diseases or thinking disorders as a consequence of taking drugs) or a serious form of pre-delinquent behavior.

\section{c) Thefts}

If somebody has an urge to get something for what he is longing for, what he wants to possess, and what does not belong to him, then it is a case of purloining to somebody else's detriment. It is frequently an intentional act in order to do harm to somebody else. A child can steal so as to be admitted into a social group, to be one of it in order not to be alone, to resist, to attract the attention of adults, to experience adventure or excitement. Thefts can be divided into occasional (impulsive, without rational deliberation of reasons and consequences), premeditated (planned with already a more serious signal of socialization disturbance), and repeated thefts in a group (members of the group do not esteem the thefts as a serious breach of norms).

\section{d) Truancy and flights}

Truancy represents a repeated unexcused absence of the pupil or student in the class. It usually develops in a group and used to have a character of the asocial up to antisocial behavior. Truancy can have several reasons: 
- school maladaptation (insufficient school preparedness of the child; neurotic problems caused by the classmates, requirements of the teacher or the school environment, and other things);

- inadequate mental level (cognitive abilities and motivationally volitional characteristics of the individual do not correspond to the type of the school; unrevealed eye and hearing disorders; learning disturbances and other things);

- influence of parents (broken home; unfavorable social relations or violence in the family; disinterest of parents in the child and other things).

About the so-called hidden truancy is spoken when the nonattendance of the child at school is tolerated by its parents (when the teacher obtains a notification that the child is ill but in reality, it spends the holiday with its parents in the middle of the school year).

Flights represent a prohibited and wilful leave of the child or adolescent from the care of people who bring it up. According to the display and motivation specifics, it can be divided into:

- reactive, impulsive flights (the flights are an impulsive reaction to a situation);

- chronic flights (these are planned and result from long-term problems);

- roving (follows the flights and used to be a prolonged leave of the home).

The primary thing in the course of truancy, flights, and wandering elimination is to break out the individual from the influence of the pathological environment, diagnose the endogenous (inside) disorder and adjust the disrupted relation to the learning by looking for the most appropriate motivation.

\section{e) Bullying}

Bullying belongs to the special forms of aggressive and manipulative behavior through which the aggressor, by virtue of physical or psychical suffering, abuse, and subjugation, gains or maintains the upper hand over the victim. Apart from bullying in the school environment also exists bullying in the workplace on the part of colleagues - mobbing, on the part of a supervisor - bossing or in the partner relations or families - domestic violence. Nowadays is greatly topical the unpleasant, hurting, and dangerous cyber-bullying (also cybernetic, computer bullying) - the designation of various forms of bullying by means of electronic media (as is the Internet and mobile phones) that serve for aggressive and deliberate repeated damage of this media user. 
Professional literature distinguishes five stages of bullying development: ostracism, physical aggression, intensification of manipulation, creation of the core, adoption of aggressors' norms, and totality, which forms absolute bullying (Kolář, 2012). Higher stages of bullying can be viewed as delinquent behavior, and therefore, it needs cooperation with the psychologists and sometimes the help of the police. There are well-known cases when the ignored or hidden bullying among schoolmates ended by serious mental disorder, injury, or suicide of the victim.

\subsection{Socially undesirable phenomena endangering the children and youth}

As socially undesirable, or as the case may be pathological phenomena, are designated such forms of behavior that have a relatively mass character and with its negative consequences endanger not only the respective individual but also the society. To this category can be primarily counted behavior addictions, more serious disturbances of the social ranking represented by the delinquency and criminality, membership in an extremist movement or religious sect, and selected disorders of self-recognition, conditioned by fashionable Euro-American trends (Jedlička, 2015, p. 354).

\section{a) Habit forming behavior and addictions}

Addiction is perceived as a more serious state of a psychical and somatic character. It results from repeated contact with the addictive substance or

112 activity that causes the addiction. It is uncontrollable by the will and rational arguments. Quite frequently, it used to be an uncontrolled reaction to a demanding life situation and psychical load.

\section{- Addiction to psychoactive substances}

There is a number of conceptions and definitions of drug addictions or addiction to addictive substances. Basically, it can be stated that it is a case of psychical or bodily addiction of an individual to a certain substance or class of substances. Centrally described characteristic of the addiction syndrome is the desire to take proactive substances, alcohol or tobacco (Nešpor, 2018).

Addiction is a diseased state with the following typical characteristics:

- uncontrollable compulsion or feeling of need to take the substance;

- bodily disturbances caused by use discontinuation of the respective substance;

- the necessity to increase the dose for getting the desirable effects;

- taking drugs in the context of neglecting duties and also leisure activities;

- standing used of the substance with being conscious of its harmfulness and serious consequences. 
Prevention of addiction to addictive substances proceeds on three basic levels:

- $\quad$ primary prevention unites all activities enabling to prevent the contact with the addictive substance and the rise of the addiction at all (lectures, leisure activities, development of self-consciousness, self-culture, and self-determination);

- $\quad$ secondary prevention means timely looking for children and adults that are in a way weakened, who are in contact with the addictive substance;

- tertiary prevention means the effort to reduce the impact of taking addictive substances and consequences of the lifestylerelated to this (medical examination of drug edicts on sexually transmitted diseases, exchange of syringes for aseptic ones, or programs of more aggressive drugs substitution by a less aggressive one, the so-called substitution therapy).

\section{- Internet addiction disorder}

Internet addiction disorder is the addiction (addictive behavior or addiction to the process) to the so-called virtual drugs. Particularly to computer games, social networks, internet services, video, mobile phones, television, and other things. The problem of internet addiction disorder represents serious health risks in the sphere of physical, psychical, and also social health. Addiction to computers and the Internet is underestimated, but it is widely spread even to small children. It concerns compulsive spending of time at the computer or Internet, reduced self-control, and also loss of the notion of the time spent at it. Children often oppose the parents' ban regarding the game. They rise early in the morning to the computer, or on the contrary, they stay up late at night, and the nervousness and restlessness at many of them are growing. The bodily risks connected with the use of computers manifest themselves, particularly in the sphere of locomotive organs and visual systems. In the sphere of locomotive organs can appear pains of the neck, shoulders, vertebral column, small joints, wrist, and so on. A further characteristic phenomenon of the internet addiction disorder is the problem of RSI (Repetition Strain Injury), a group of disabilities that are caused by small repeated movements at work on the computer. The common character for all kinds of disabilities is substantial painfulness. To these disabilities belongs inflammation of the tendon cover, inflammation of the tendon itself, and inflammation of the non-articular prominence. A sedentary lifestyle can also be connected with further problems, for example, obesity, diabetes, and heart disease. Working at the monitor in the sphere of the visual system can cause the so-called syndrome of the computer seeing that causes pains of eyes (smarting, tearing, the occurrence of tics, spots before eyes, redness of eyelids). To these issues also belong pains of the head, back, and neck. 
- Pathological gambling on gambling machines

It concerns a relatively new form of addictive behavior, and in adolescents, it is usually connected with the joy of gaming and feeling of satisfaction from overcoming the opponent. The game on gaming machines causes similar changes as the drugs (weakening of the will, impulsiveness and aggression, neglecting of the study and also working duties, the disintegration of social relations, and other things). If there is no timely action taken at the adolescent in the form of therapy and social psychological intervention, the addiction can end in complete psychical, physical, and economical collapse.

\section{- Addictions to religious sects and psychical cults}

The sect used to be described as a numerically small, at the beginning, especially religiously-oriented group, constituted as a critical and dissatisfied opposition in relation to the traditional church or respected ideology. It used to be characterized by the following features:

- authoritativeness of leading figures (emphasis on the acceptation of the norms and obedience);

- secretiveness (isolationism and communication with the surroundings on a pragmatic level);

- concealing of the organizational structures ( possibly the doctrine as a whole);

- fundamentalism (intolerance towards the different or critical opinions).

Classification of the main specializations can be divided into:

- $\quad$ sects with a Christian basis;

- $\quad$ sects with an eastern basis;

- $\quad$ sects with an "occult" basis;

- $\quad$ sects with a "psychotherapeutic" basis.

As a consequence of a young man's contact with the sect used to be changed the social relations and also the system of values and norms, which is then significantly reflected in the change of behavior, thinking, emotions and will.

\section{b) Disturbances of self-perception connected with the damaging lifestyle}

One of the substantial factors of the undesirable behavior of children and youth is doubts about their own value. The doubts create not only its casual background but also determine the final aspect: by the negative display of behavior, the pupil and pubescent try to avoid the threatening failure and negative evaluation, but sometimes they try to exact proof of their own importance from the surroundings, the so-called policy of prestige.

\section{- Eating disturbances}


To the eating disturbances belong:

- bulimia (repeated episodes of overeating concluded by stomachache and vomiting as a compensation manoeuvre);

- mental anorexia (absence of appetite connected with the restriction up to refusing of food, with fear from obesity even at the extremely low weight);

Behind mental anorexia and bulimia are predominantly hidden problems with self-evaluation, characteristics, and excessive interest in bodily appearance and weight or inability to establish satisfactory relations with peers. The remedy requires a complex therapy, including psychotherapy, as the efficacy of the preventive educational work depends for the most part on a good example that is, from the view of adolescents, trustworthy and worthy of following.

\section{- Bigorexia}

Muscular dysmorphia is a behavior disturbance resulting from the inferiority complex that is in boys and young men manifested by a pathological dependency on exercising and the desire to have an attractive muscular figure. The bodybuilding exercise used to be continued even in the case of inflammation or injury of tendons and muscles.

\section{- Sexual deviations and prostitution}

Sexual deviations are behavior disturbances connected with the satisfying of man's sexual needs. It is difficult to diagnose and classify it from the viewpoint of its display, importance, and social dangerousness but also by the conception of "normality" of sexual behavior (Weiss, 2008).

Among basic disturbances of the sexual behavior can be rated fetishism, narcissism, voyeurism, exhibitionism, transvestism, and then more serious up to pathological disturbances seem to be sadism, masochism, pedophilia, and necrophilia. To the socially ethically and legally unacceptable forms of sexual behavior also belongs incest (sexual intercourse between close relatives, principally between parents and children or between siblings).

A relevant problem of the contemporary youth seems to be the sexual promiscuity that consists in frequent changing of sexual partners when making contact with the partners is accidental, and the sexual intercourse occurs without emotional attachment. Promiscuity behavior frequently precedes prostitution that can be designated as providing sexual services for money or another reward. "Entrepreneurship with one's own body" in adolescence concerns young men and also girls the prostitution can be both heterosexual and homosexual.

Due to the enlightenment and growing tolerance to certain phenomena of sexually motivated behavior came a substantial change of the stand on certain 
forms of sexual behavior. This fact concerns principally masturbation (selfabuse, onanism) and homosexuality that is today understood as a form of normal sexual behavior.

The possibilities of education, besides the enlightenment, can be seen in the implementation of sexual and partnership education into schools, and likewise in the appropriate education of teachers in this sphere both in professional and content terms and also methodical aspects.

\section{c) Disturbances of the social inclusion}

It concerns behavior disturbances that are connected with problems of the individual' s inclusion into the social environment and are characterized by a high level of social dangerousness.

\section{- Criminality}

Criminality used to be defined as the occurrence of the criminal behavior expressed as a summary of the criminal offenses committed on a certain territory in a defined period of time. In view of the fact that various cultures differ in their values or norms, also differs the opinion what is considered as a criminal offense.

The criminality of the youth - juvenile delinquency - forms a part of the total criminality. It has its specifics due to the total immaturity and incompleteness of the psychosocial development of the adolescents. The offender's characteristic feature in committing criminal offenses used to be disturbed relations to the society, to work, and also to education. Personal characteristics also play an important role. It is, for example, a weak volitional control, heightened impulsivity, but also mutual instigation to the consumption of alcohol. The analyses of delinquent behavior and criminal offenses take particularly into account the age of the offenders, sex, social origin, and also the place of committing the antisocial activities.

Criminal offenses of adolescents used to be punished according to their nature, seriousness, and the age of the offender by placement into young offenders' institutions, penal facilities, or alternative punishment by noncustodial sentence.

\section{- Vandalism}

Vandalism is wilful purposeful destruction of things, the hidden purpose of which is venting of the accumulated tension and aggressiveness. Most frequently, it possesses a group or mass character. It is displayed by the destruction of cultural values and the damaging of valuable objects belonging to private persons or society. The behavior of vandals can have a wholly clear target (for example, revenge), when the acting individual willfully destroys the value of the damaged property, or the behavior is a form of the inappropriate game (fulfillment of leisure time and boredom, demonstration 
of strength), when the acting individual does not altogether take an interest in the value of the damaged property (broken down traffic signs, broken trees in the parks, broken windows at the bus stops and so on). In the cure of vandal, youngsters proved to be useful the community services as alternative punishments, when the rioters must remove the damage themselves.

\section{- Graffiti}

Graffiti is a sort of art when the drawings or signs are sprayed by spray colors on the walls or other surfaces. The selected place for spraying should catch the attention of passers-by as much as possible (houses, historic buildings, statues, monuments, railway wagons, underground, .bridge constructions, and other things). The writer can paint on his own what does not usually happen or in a crew. According to the attitude of the majority to the surface on which the work was created, the graffiti creation is usually divided into legal (for example, decoration of the contact center building, advertising billboards, panel walls approved by the municipal authority) and illegal (tram stops, cemetery wall, block of flats and similar surfaces). Spraying carried out by adolescents used to be interpreted as the need for their self-expression and searching for identity. Nevertheless, from the point of view of those affected by spraying, it is considered as damaging of the property, and in the case of spraying culture monuments, it could be assessed as a criminal delict.

\section{- Street violence and extremist movements}

As extremist are designated groupings avowing extreme and eccentric opinions aiming at suppression of civil rights political and religious liberty. The extremists often publicly manifest nationalistically oriented fundamentalism that is accompanied by xenophobe tendencies and racial intolerance. Inside of the grouping are most of all appreciated loyalty, orthodoxy towards avowed opinions and values, unquestioning obedience towards the authority, intolerance towards divergences, and fighting spirit. Its members get emotional support from like-minded peers (for example, supporters of the rowdies club, followers of the skinhead movement, and street gangs). Experience of togetherness with a strong unit is intensified during actions where it is possible to vent the tension and anxiety by the approved form of aggression (during chanting on the stadiums, demonstrations, celebrations, and concerts of specific music groups). Various forms of extremism used to be connected with street violence.

\section{- Self-harming and self-destruction behavior}

Self-harming constitutes a number of concrete phenomena of behavior with various levels of seriousness, resulting from the need for intentional injuring of one's own health. To this pertains self-injuring, swallowing of foreign bodies, malingering of diseases and injuries, self-destruction attempts. It can result from the need to make one's presence felt or escape from the insoluble or inconvenient situation. It expresses disturbances of the relation to oneself in consequence of the social, eventually psychogenic factors.

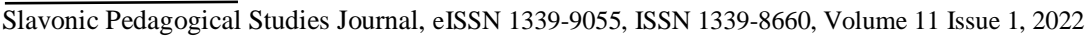


Self-destruction constitutes a wilful ending of one's own life by a spontaneous act that shall cause death. It usually constitutes a reaction to a depressing life situation connected with loss of the meaning of life, disappointment, failure, disturbance of self-preservation. It is also connected with the psychical instability of the personality and with the incidence of psychical diseases. The stimulus to self-destruction behavior at children used to be the fear before punishment and anger of parents (failure at school), fear of cruelty or sexual harassment, unhappy love in the puberty, and later it is a case of inability to solve a conflict, manage deep human loneliness and hopeless prospects. The support of healthy self-consciousness, self-esteem, and mutual respect should form a natural part of school activities.

\section{Conclusion}

In the course of prevention, diagnostics, re-education, and pedagogical psychological support of children and adolescents in difficult life situations, it is necessary to keep in mind that display of their behavior, kinds of their thinking, and specifics of their experience are always complicatedly conditioned by many mutually intensifying or on the contrary neutralizing circumstances. The school as an institution, the management of the school, and also the team of pedagogues can do many positive things for the youth, but one thing they cannot do for sure - replace a non-functioning family, correct sensation-seeking media, and substitute the activity of other social structures.

\section{Bibliographic references}

Jedlicka, R. and the team of authors. (2015). Poruchy socializace u dětí a dospívajících (Disturbances of socialization at the children and youth) . Prague: Grada.

Kolar, Z. and the team of authors. (2012). Výkladový slovník z pedagogiky (Monolingual dictionary of pedagogy). Prague: Grada.

Kovarikova, M. (2020). Krizové situace ve škole (Crisis situations at school).Prague: Grada.

Nespor, K. (2018). Stř́źlivě, většinou vesele (Soberly, for the most part cheerfully). Prague: Portál.

Prucha, J, and the team of authors.(2009). Pedagogická encyklopedie. (Pedagogical encyclopaedia). Prague: Portál.

Valisova, A. \& Kasikova, H. and the team of authors. (2016). Pedagogika pro učitele (Pedagogy for teachers). Prague: Grada.

Weiss, P. (2008). Sexuální deviace (Sexual deviations). Prague: Mladá fronta.

Prof. PhDr. Alena Vališová, CSc.

Institute of Education and Science VŠCHT

Prague

Czech Republic

alenaval@atlas.cz 